\title{
Thermal Comfort Condition of Passengers in Naturally Ventilated Train Stations
}

\author{
Junta Nakano ${ }^{1}$ and Shin-ichi Tanabe ${ }^{2}$ \\ ${ }^{1}$ Tokai University, Department of Architecture, 4-1-1 Kitakaname, Hiratsuka, Kanagawa, Japan \\ ${ }^{2}$ Waseda University, Department of Architecture, 3-4-1 Okubo, Shinjuku, Tokyo, Japan
}

\begin{abstract}
Train is the most frequently used means of transportation in Tokyo. Train stations are gaining attention as commercial complex today, and higher level of comfort is being demanded for the indoor environment. Open structure of the train station and semi-outdoor like environment suggest that the thermal comfort condition is relaxed compared to indoor comfort standards. The objective of this study is to investigate the thermal comfort condition within train stations and to clarify the appropriate target for environmental control. Field surveys were carried out in summer, autumn and winter during July 2004 to August 2006 in four train stations located in urban area of Tokyo. Concourses were not air-conditioned except one station where spot cooling was operated in summer near the ticket gate. Each survey was conducted from 7:00 to 20:00 for 3 to 11 days per season per station for a total of 81 days. The survey consisted of thermal environment measurement and thermal comfort questionnaire. More than $80 \%$ of passengers felt thermally comfortable within the range of 19 to $29{ }^{\circ} \mathrm{C} \mathrm{SET} *$. However, acceptability zone was found to be 19 to $32{ }^{\circ} \mathrm{C}$ SET $^{*}$, and it is recommended to design naturally ventilated train stations to fulfil this target.
\end{abstract}

\section{INTRODUCTION}

Train is the most frequently used means of transportation in Tokyo. Most of the existing train stations in the urban area were built or rebuilt after 1950's with a pragmatic objective to realize efficient mass passenger flow for rapidly growing population. Economic efficiency had a high priority and less attention was paid to the indoor environmental quality. However, stations today are gaining attention as commercial complex where large number of people gather every day. Higher level of comfort is being demanded for the indoor environment including thermal comfort.

On the other hand, open structure of the train station and semi-outdoor like environment suggest that the thermal comfort condition is relaxed compared to indoor comfort standards. The objective of this study is to investigate the thermal comfort condition in naturally ventilated train stations to clarify the appropriate target for environmental control.

\section{METHODS}

\subsection{Outline of Survey}

Field surveys were carried out in summer, autumn and winter during 2004 to 2006 in a total of four train stations located in Tokyo. Overview of the station are presented in Table 1. Concourses were not air-conditioned except Station M where spot cooling was operated in summer near the ticket gate. Each survey was conducted from 7:00 to 20:00 for 3 to 11 days per season per station for a total of 81 days. The survey consisted of thermal environment measurement and thermal comfort questionnaire.

Table 1. Overview of train stations.

\begin{tabular}{l|c|c|c|c}
\hline & Station S & Station M & Station U & Station T \\
\hline \hline Location & Tokyo & Tokyo & Tokyo & Tokyo \\
\hline Floor area $\left(\mathrm{m}^{2}\right)$ & 1,300 & 1,100 & 20,000 & 4,800 \\
\hline Ridership/day & 84,000 & 76,000 & 186,000 & 148,000 \\
\hline Questionnaires & 445 & 685 & 1053 & 1894 \\
\hline Survey year & 2004 & 2004 & 2004 & 2006 \\
\hline
\end{tabular}

\subsection{Thermal Environment Measurement}

A mobile measurement cart equipped with batteries for a full-day operation was devised to measure air temperature, humidity and air velocity around the occupant at a height of $1.1 \mathrm{~m}$ above floor level. Radiant environment was evaluated by measuring directional total radiation $(0.3$ $4.0 \mu \mathrm{m}$ ) for six directions (up, down, front, back, left, right) at $1.1 \mathrm{~m}$ above floor level. Environmental parameters were recorded every 10 seconds.

Air temperature and humidity trends were recorded every 20 minutes during each survey period to observe the

\footnotetext{
* Corresponding author: jnakano@tokai.ac.jp
} 
environmental characteristics in concourses for 5 to 10 locations.

\subsection{Thermal Comfort Questionnaire}

Thermal comfort questionnaire survey was conducted on actual passengers of each station. Random passengers standing in the concourse were asked to answer their background information and subjective evaluation of thermal environment on a tablet PC. The main subjective evaluation scales used for thermal comfort evaluation are given in Table 2. Seven-point thermal sensation vote, three-point thermal preference vote, seven-point overall comfort vote, and two-point acceptability vote were employed. The shaded scales in the table show the criteria for binary classification of each vote used in the later analysis.

After earning the consent of an occupant to answer the questionnaire, another surveyor pushed the mobile measurement cart near the respondent to measure the surrounding environment for three minutes. Thirtysecond average prior to the end of each measurement was regarded as the representative thermal environment for that respondent. Clothing items were recorded on a checklist ${ }^{1)}$ by visual observation of the surveyor. A total of 4,077 answers and corresponding sets of environmental data were collected. The number of collected data for each station is given in Table 1.

Table 2. Subjective scales for thermal comfort evaluation.

\begin{tabular}{|c|c|c|c|}
\hline Thermal sensation & Preference & Overall comfort & Acceptability \\
\hline Hot & \multirow{3}{*}{ Cooler } & $\begin{array}{c}\text { Very } \\
\text { comfortable }\end{array}$ & \multirow{4}{*}{ Acceptable } \\
\hline Warm & & Comfortable & \\
\hline $\begin{array}{c}\text { Slightly } \\
\text { warm }\end{array}$ & & $\begin{array}{c}\text { Slightly } \\
\text { comfortable }\end{array}$ & \\
\hline Neutral & As it is & Neutral & \\
\hline $\begin{array}{l}\text { Slightly } \\
\text { cool }\end{array}$ & \multirow{3}{*}{ Warmer } & $\begin{array}{c}\text { Slightly } \\
\text { uncomfortable }\end{array}$ & \multirow{3}{*}{$\begin{array}{c}\text { Not } \\
\text { acceptable }\end{array}$} \\
\hline Cool & & Uncomfortable & \\
\hline Cold & & $\begin{array}{c}\text { Very } \\
\text { uncomfortable }\end{array}$ & \\
\hline \multicolumn{2}{|c|}{ * not preferred } & discomfort & not acceptable \\
\hline
\end{tabular}

\section{RESULTS}

\subsection{Thermal Environment}

Mean value and standard deviation of thermal environment parameters are given for each season in Table 3. These values describe the occupied environment of the passengers who responded to the questionnaire survey. Air temperature and mean radiant temperature were higher in the order of summer, autumn and winter.
Air velocity and humidity showed minor differences between seasons. Observed clothing insulation was 0.5 , 0.8 , and 1.3 clo for summer, autumn, and winter respectively.

SET* (Standard New Effective Temperature) was calculated for each respondent using the measured environmental values. Metabolic rate of 1.6 met was assumed as all the respondents were standing shortly after walking to the concourse. The results are given in Table 3.

Table 3. Summary of environmental parameters.

\begin{tabular}{lc|c|c|c}
\hline & & Summer & Autumn & Winter \\
\hline \hline Air temp. & avg. & 29.7 & 22.8 & 11.8 \\
$\left({ }^{\circ} \mathrm{C}\right)$ & s.d. & 3.7 & 2.7 & 2.3 \\
\hline Air velocity & avg. & 0.31 & 0.33 & 0.30 \\
$(\mathrm{~m} / \mathrm{s})$ & s.d. & 0.14 & 0.14 & 0.11 \\
\hline MRT & avg. & 31.6 & 24.9 & 14.2 \\
$\left({ }^{\circ} \mathrm{C}\right)$ & s.d. & 3.5 & 2.8 & 2.5 \\
\hline Humidity & avg. & 56 & 55 & 42 \\
$(\%)$ & s.d. & 9 & 15 & 21 \\
\hline Clothing & avg. & 0.5 & 0.8 & 1.3 \\
$($ clo $)$ & s.d. & 0.1 & 0.3 & 0.2 \\
\hline SET $*$ & avg. & 30.7 & 26.5 & 21.5 \\
$\left({ }^{\circ} \mathrm{C}\right)$ & s.d. & 2.9 & 2.3 & 2.4 \\
\hline
\end{tabular}

Relative frequency distribution of operative temperature is given in Fig.1 for each season. Distribution of summer and autumn shows two peaks, and winter results also shows uneven distribution, reflecting the outdoor climate conditions of the survey days.

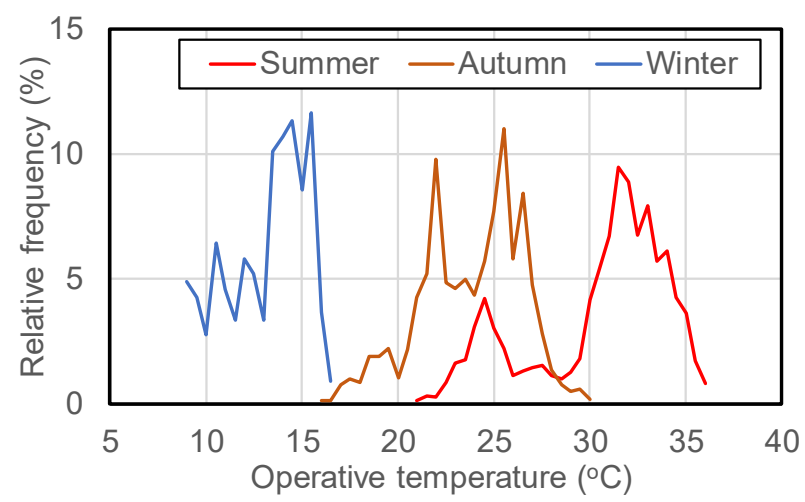

Fig. 1. Relative frequency distribution of operative temperature in the occupied zone.

Relative frequency distribution of SET* is given in Fig.2. SET* was distributed normally around a singular 
peak. Behavioral adaptation in the form of clothing adjustment led the passengers' thermal environment to settled around certain mean value for each season.

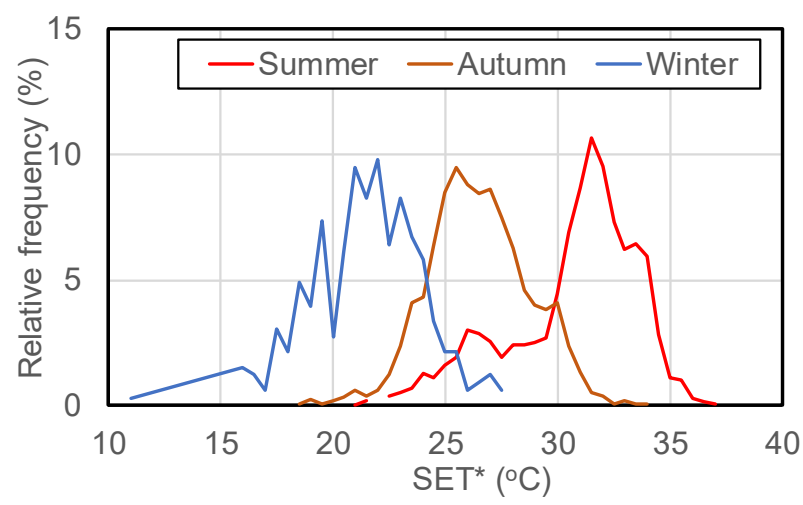

Fig. 2. Relative frequency distribution of SET* in the occupied zone.

\subsection{Thermal Comfort Questionnaire}

\subsubsection{Background of Respondents}

Background of questionnaire respondents are presented in Fig. 3. Age groups ranged from 10's to over 60's. Group of 20's was the largest, $29 \%$ of whole. Female respondent population was 1.3 greater than males. Questionnaires were collected from passengers with widely distributed backgrounds.

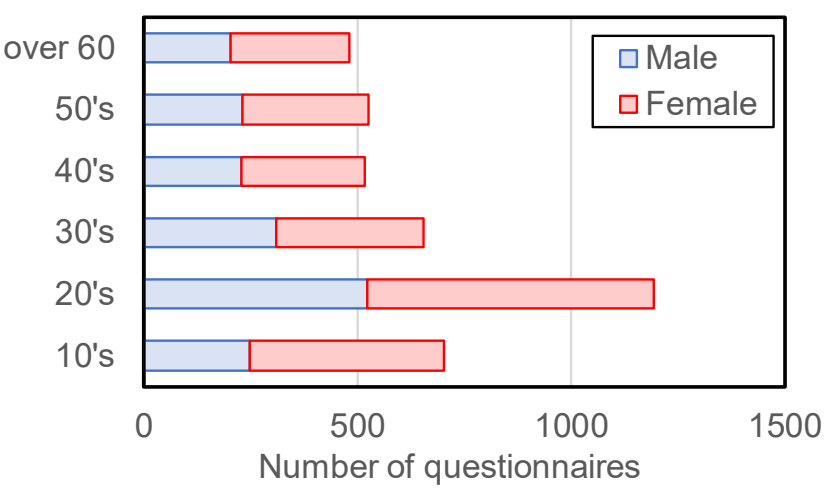

Fig. 3. Background of questionnaire respondents.

\subsubsection{Overall Comfort}

Seven-point scale overall comfort vote was categorized into "comfortable" and "uncomfortable" as described in Table 2. Percentage of comfort vote is given in Fig. 4. The numbers written in bars show the actual number of votes. Percentage of "comfortable" was higher in the order of winter, autumn, and summer. The highest value was $78 \%$ and the lowest value was $59 \%$. Eighty percent comfort criteria could not be met for all three seasons.

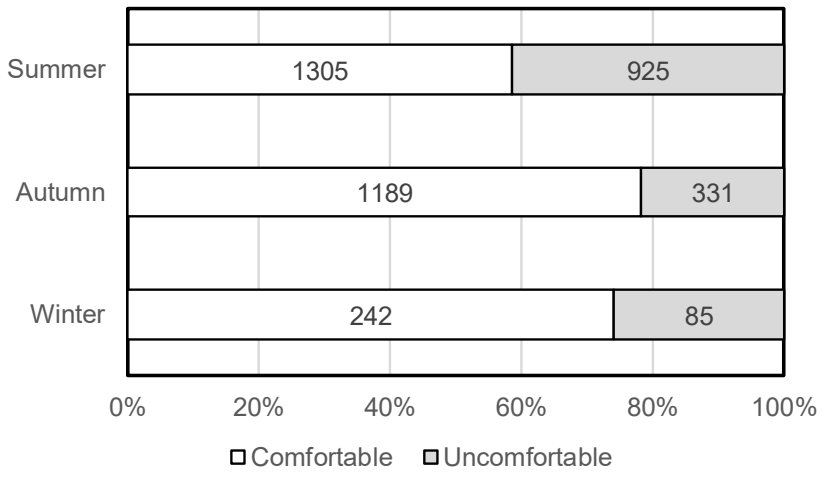

Fig. 4. Percentage of overall comfort vote.

\subsubsection{Acceptability}

Percentage of acceptability vote is given in Fig. 5. More than $80 \%$ of the passengers voted the environment to be acceptable in all seasons. Order of seasonal acceptability rate was the same as the comfort vote.

Results of overall comfort and acceptability votes showed that environment of train stations is considered acceptable, but not comfortable. Summer season tended to be rated the lowest of all seasons.

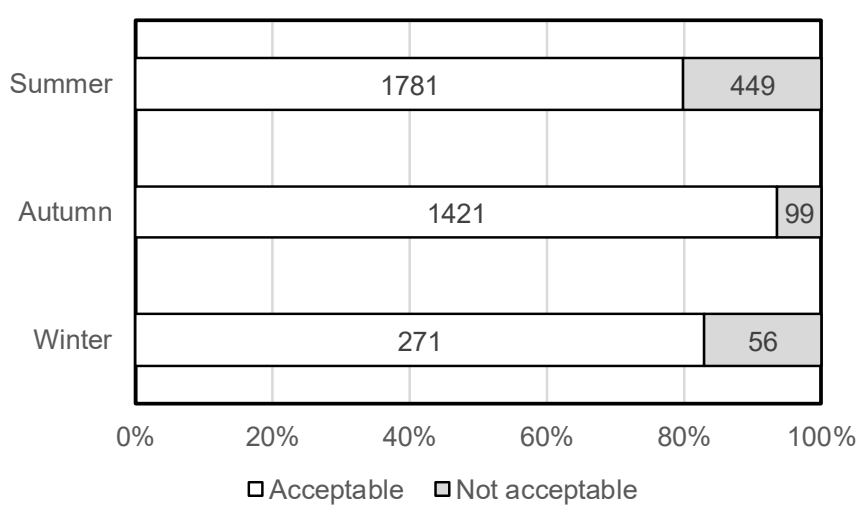

Fig. 5. Percentage of acceptability vote.

\subsection{Neutral Temperature}

Environmental temperature for each respondent was divided into $0.5^{\circ} \mathrm{C}$ increments, and mean value of thermal sensation vote (TSV) falling in the same temperature category was derived. Mean TSV is plotted against operative temperature in Fig.6. Temperature category with respondents less than 10 was omitted from analysis. Size of the bubble depicts the number of population in the category. Determination coefficient of linear regression was 0.95 . Neutral operative temperature of yearly analysis was found to be $21.0^{\circ} \mathrm{C}$.

Deviation of plots from regression was large within the range of 20 to $30^{\circ} \mathrm{C}$ where summer and autumn data were 
mixed. Although $r^{2}$ value was high, alternative environmental parameter may be more suitable to describe thermal sensation of passengers.

Mean TSV is plotted against SET* in Fig.6. Determination coefficient of linear regression was 0.98 , showing better fit than operative temperature. Neutral SET* $^{*}$ of yearly analysis was found to be $25.0^{\circ} \mathrm{C}$.

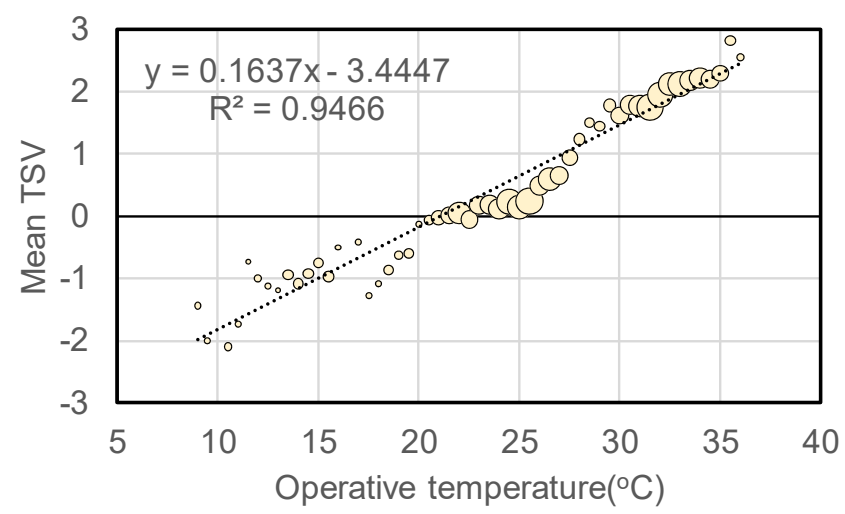

Fig. 6. Operative temperature and mean thermal sensation vote.

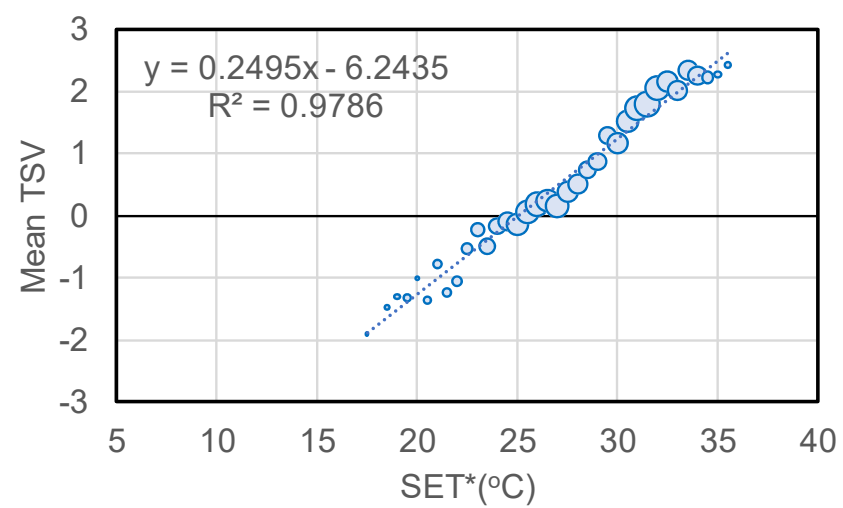

Fig. 7. SET* and mean thermal sensation vote.

Neutral temperature is a useful information to determine the set-point temperature for air-conditioning. However, in semi-outdoor environment where indoor environment is continuously drifting, "comfort zone", not "comfort temperature" is more important for environmental planning. The following analysis seeks to determine the comfort zone from subjective evaluation and environmental measurement of field survey.

\subsection{Thermal Preference}

PPD (Predicted Percentage of Dissatisfied) prediction lies on an assumption that central three categories, $-1,0$, and 1 , of seven-point thermal sensation scale is comfortable ${ }^{2}$. This hypothesis was tested using TSV and preference vote from the present survey. Percentage of "want cooler" vote and "want warmer" vote is plotted against thermal sensation vote of the same respondent in Fig.8. Figures are presented for each season separately.
In summer, less than $20 \%$ preferred the environment to be warmer regardless of thermal sensation. On the other hand, $60 \%$ preferred to be cooler at "slightly warm $(+1)$ ". The trend was quite the opposite in winter, and $60 \%$ preferred to be warmer at "slightly cool (-1)". Autumn results showed an intermediate characteristic.

Meaning of "warm" and "cool" included in thermal sensation scale was evidently affected by seasonal context. People preferred to be "cooler" in summer and "warmer" in winter. Because these words are included in the central three categories of thermal sensation vote, other ways to determine the actual comfort condition is required.

Preference vote was adopted to be more suitable than thermal sensation vote to consider the seasonal semantic difference of thermal sensation. "Warmer" and "cooler" vote was paired with overall discomfort (slightly uncomfortable, uncomfortable, very uncomfortable) and unacceptability (not acceptable) votes to determine the actual "thermal discomfort" and "thermal unacceptability".

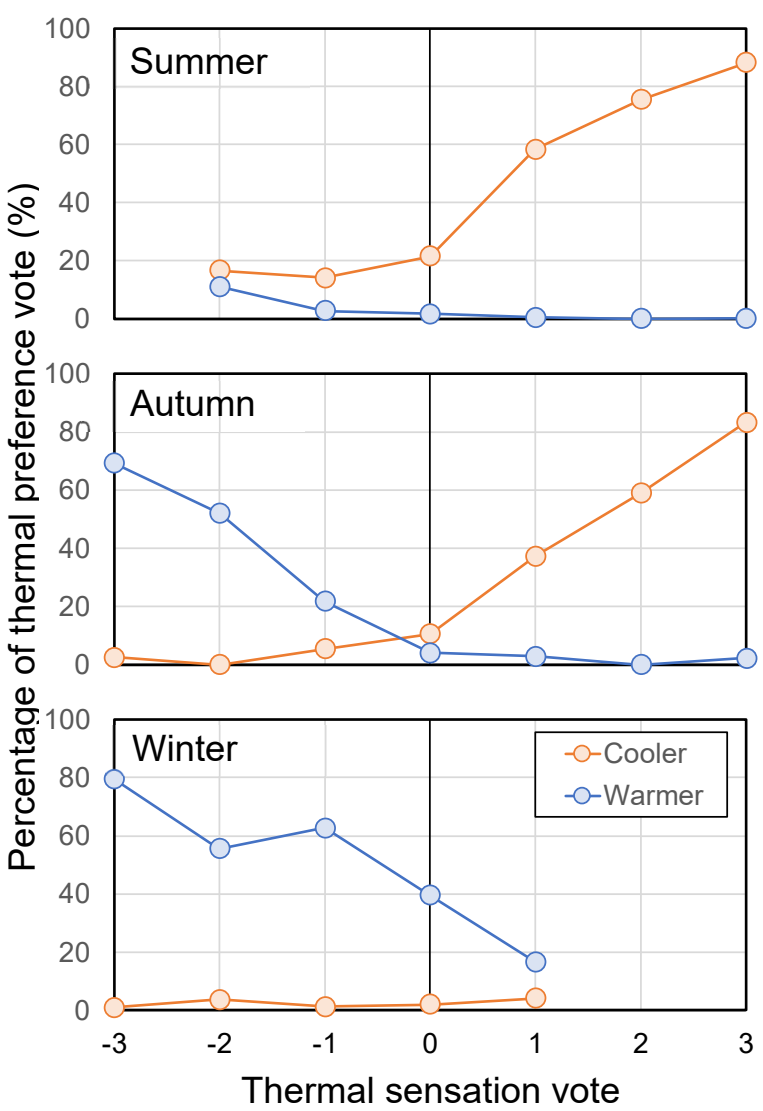

Fig. 8. Thermal sensation vote and percentage of thermal preference vote.

\subsection{Thermal Comfort Zone}

SET* was rounded into $0.5^{\circ} \mathrm{C}$ units, and percentage of vote was derived from a group of respondents in the same temperature category. All the seasonal data were integrated in the analysis. Categories whose $n<10$ were excluded from further analysis. 
Probit curve fit was applied to percentage plots for warmer and cooler side separately. The two curves were then added to derive a single curve. Thermal comfort curve and thermal acceptability curve are given in Figure 3. PPD curve calculated for standard environment $(\mathrm{ta}=\mathrm{tr}$, $\mathrm{v}=0.1 \mathrm{~m} / \mathrm{s}, \mathrm{rh}=50 \%, 1.6$ met, 0.6 clo) is shown as reference.

Thermal discomfort curve is presented in Fig.9. The red dot shows the percentage of respondents who voted the thermal preference to be "cooler" and overall comfort to be "uncomfortable" at the same time in each temperature category. The value is circa zero around $20{ }^{\circ} \mathrm{C}$ but rose gradually as temperature increased. Percentage of warm discomfort exceeded $20 \%$ at SET $* 29^{\circ}$ C. Similarly, the blue dot shows the percentage of cool discomfort. The temperature at which this percentage crosses over $20 \%$ was $19^{\circ} \mathrm{C}$. Adding these 2 curves yields the integrated

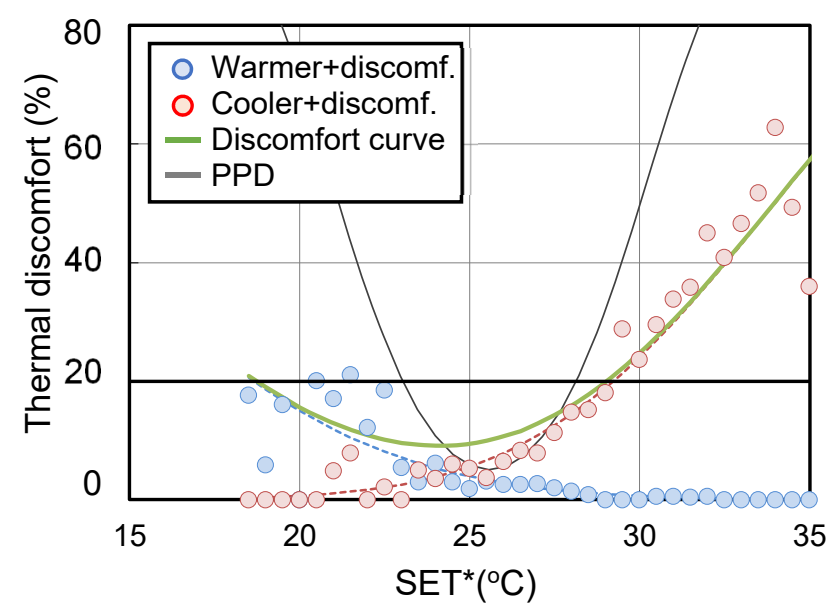

Fig. 9. Thermal discomfort curve.

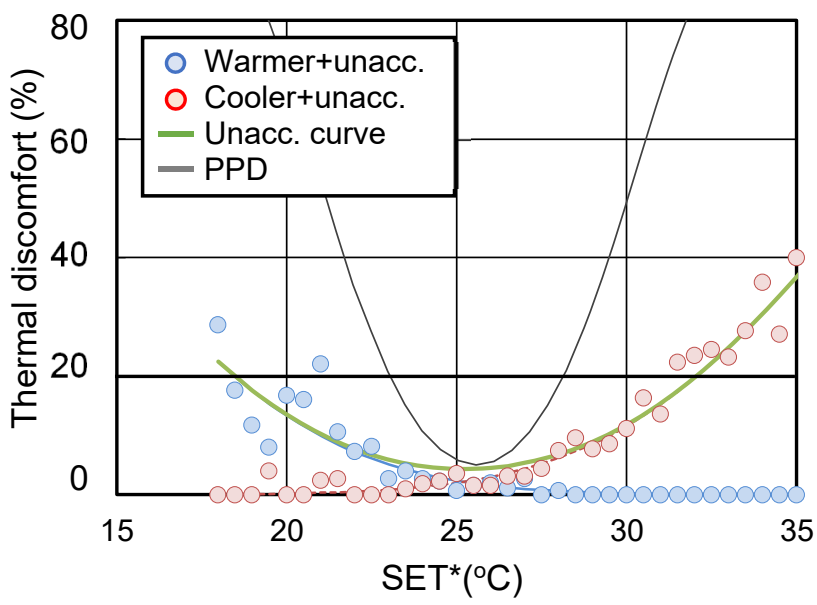

Fig. 10. Thermal unacceptability curve.

thermal discomfort curve drawn in green. If the $20 \%$ discomfort criteria adopted by ASHRAE 55 standard $^{3)}$ were to be employed, the comfort zone would be from 19 ${ }^{\circ} \mathrm{C}$ to $29^{\circ} \mathrm{C}$ in SET*. On the other hand, the comfort zone predicted by PPD, the grey curve, was $23{ }^{\circ} \mathrm{C}$ to $28^{\circ} \mathrm{C}$.
The same approach was applied to the percentage of thermal preference and acceptability votes in Fig 10 . The green curve describes the thermally unacceptable curve. Note that the gradient of unacceptable curve is relaxed compared to the thermal discomfort curve. The lowest percentage of discomfort was $9 \%$ while the lowest value for unacceptability was $4 \%$. The $20 \%$ unacceptable zone was found to be $19{ }^{\circ} \mathrm{C}$ to $32{ }^{\circ} \mathrm{C}$.

\section{DISCUSSIONS}

Open structure of train stations prohibits the indoor thermal environment to be controlled at a fixed temperature as in air-conditioned buildings. Semi-outdoor environment falls in between environmental engineering categories of "indoor environment" where thermal environment is controlled to satisfy thermal comfort of occupants, and "outdoor environment" where occupants need to adjust themselves to achieve thermal comfort ${ }^{4}$. Design of semi-outdoor thermal environment is distinct in a way that it integrates architecture, equipment and thermal adaptation of occupants to allow for a wider range of thermal environment compared to indoor environment. The design objective would not be to maintain the environment around a set point temperature, but to maintain within a relaxed range for the majority of the concerned period. Information on comfort zone is more important than comfort temperature for the design criteria of semi-outdoor thermal environment.

Adaptive thermal comfort approach proposed by de Dear et al. ${ }^{5)}$ and Nicol et al. ${ }^{6}$ ) was adopted to derive the thermal comfort condition from field surveys in real life environment. Subjective evaluation of thermal environment and simultaneous measurement of the occupied zone throughout seasons in 4 naturally ventilated train stations yielded 4,077 sets of data.

Distribution of operative temperature in the occupied zone showed several peaks within a season, depending on the outdoor conditions of the survey day. On the other hand, SET* calculated for each questionnaire respondent was distributed normally around a mean value of each season. Behavioral adaptation, mainly clothing adjustment, was found to be effective in shifting the thermal environment of occupied zone to a limited range in SET*.

Questionnaire survey showed that $80 \%$ of passengers found the environment to be acceptable, but not necessarily comfortable. Evaluation tended to be lower especially in summer. Neutral temperature was derived using operative temperature and SET* of the occupied zone and corresponding thermal sensation vote. However, neutral temperature is not a sufficient information for planning of naturally ventilated train stations where temperature is constantly drifting. Instead, comfort zone was determined from actual subjective evaluation votes of passengers. 
The term "warm" and "cool" in thermal sensation scale was found to be strongly affected by seasonal context. An assumption to regard the three central categories of thermal sensation vote to be thermally comfortable was inappropriate in semi-outdoor environment. Thermal preference vote was paired with overall comfort vote and acceptability vote.

Thermal discomfort curve and thermal unacceptability curve were derived from SET* of occupied zone and corresponding percentage of votes. The $20 \%$ criteria adopted by ASHRAE 55 standard was employed for comfort zone. Thermal comfort zone is presented in Table 4. Comfort zone derived from the current study was twice wider than that predicted by PPD. Naturally ventilated buildings tend to have relaxed comfort zone compared to air-conditioned buildings as described in thermal comfort standards $^{3}$. Concourse in train stations is not intended for occupancy of long hours, and expectations of passengers may not be as high as that for offices. If passengers were to stay in train station for a continuous period, enclosed waiting spaces or shops with air-conditioning should be planned.

Acceptability zone was $3{ }^{\circ} \mathrm{C}$ wider than the comfort zone. The difference was observed for the upper limit, but not for the lower limit. Clothing adjustment is less effective in hot environments, and precautions are needed to fulfil the upper limit in designing naturally ventilated train stations. It is recommended to apply the "acceptability zone" for minimum requirements and "comfort zone" for higher comfort.

These results may apply to other spaces with similar context in terms of occupancy period, climate, and culture.

Table 4. Comfort zone for naturally ventilated train stations.

\begin{tabular}{l|c|c|c}
\hline & $\begin{array}{c}\text { Lower limit } \\
\left({ }^{\circ} \mathrm{C}\right)\end{array}$ & $\begin{array}{c}\text { Higher limit } \\
\left({ }^{\circ} \mathrm{C}\right)\end{array}$ & $\begin{array}{c}\text { Temperature } \\
\text { range }\left({ }^{\circ} \mathrm{C}\right)\end{array}$ \\
\hline \hline PPD & 23 & 28 & 5 \\
\hline Comfort zone & 19 & 29 & 10 \\
\hline Acceptability zone & 19 & 32 & 13 \\
\hline
\end{tabular}

\section{CONCLUSIONS}

Thermal comfort conditions of passengers in naturally ventilated train stations were investigated to clarify the appropriate target for environmental control. Field survey consisted of subjective evaluation of thermal environment and simultaneous measurement of the occupied zone. Four naturally ventilated train stations were studied throughout seasons. The entire survey lasted 81 days and 4,077 sets of data were collected. Clothing adjustment was found to be effective in shifting the personal thermal environment of occupied zone to a limited range in each season. Thermal comfort zone was determined from SET* (Standard New Effective Temperature) of occupied zone and corresponding percentage of thermal preference, overall comfort, and acceptability votes. The $20 \%$ criteria yielded thermal acceptability zone of $19-32{ }^{\circ} \mathrm{C}$ and comfort zone of $19-29{ }^{\circ} \mathrm{C}$. Temperature ranges were twice wider than the range predicted by PPD (Predicted Percentage of Dissatisfied). It is recommended to apply the "acceptability zone" for minimum requirements and "comfort zone" for higher comfort in designing thermal environment of naturally ventilated train stations.

\section{References}

1. ISO 9920:2007 Ergonomics of the thermal environment -- Estimation of thermal insulation and water vapour resistance of a clothing ensemble (2007)

2. Fanger, P.O., Thermal Comfort, Danish Technical Press (1970),

3. ASHRAE, ANSI/ASHRAE Standard 55-2017, Thermal environmental conditions for human occupancy (2017)

4. Nakano, J. and Tanabe, S., Thermal Comfort and Adaptation in Semi-Outdoor Environments, ASHRAE Transactions, Vol.110(2), pp.543-553 (2004)

5. de Dear, R.J. and Brager, G.S., The adaptive model of thermal comfort and energy conservation in the built environment, International Journal of Biometeorology, 45, pp.100-108 (2001)

6. Nicol, J.F. and Humphreys, M.A., Derivation of the adaptive equations for thermal comfort in freerunning buildings in European standard EN15251, Building and Environment, 45, pp.11-17 (2010) 